\title{
Exploring the Key Challenges: Adaptability, Sustainability, Interoperability and Security to M-Payment
}

\author{
doi:10.3991/ijim.v5i2.1435 \\ Rashmi Mantri and Junkang Feng \\ University of the West of Scotland, UK
}

\begin{abstract}
Any payment which uses mobile device as payment method is called M-payment whether it is proximity or remote and online or point of sale. Since it has been identified that mobile phone is everywhere and everpresent essential consumer device, and could be used for payment offline or online, Mobile payment has been hyped significantly. However early market adoption is facing some challenges and in need of the unanimous effort of all key players (manufacturers, mobile operators, merchants and customers) of value chain in order to accept mobile payment method and achieve standard and sustainable business model. Achieving one business model is important for user convenience and reachability, resulting in increased market opportunities.
\end{abstract}

Index Terms-Mobile-payment, Value Chain, NFC, RFID, Customer Adaptability, Sustainability, Interoperability, Mpayment Security and Trust, etc.

\section{INTRODUCTION}

The Aim of this research is to know the main challenges to the new payment system called Mobile payments. Proper literature review is done for sound understanding and proper analysis of the subject. Two way surveys will be done one for demand side (to know consumer adaptability) and other for supply side (to know the providers concerns). Solution will be provided based on the results of above studies. The main focus of this research proposal is that why cohesive technologies are needed and how it could be achieved? Some M-payment ventures are successfully working in Japan, US and Asian countries such as NTT DoCoMo and PayPal M-payments. The main reason of M-payment adoption among consumers in those countries is that their security issues are dealt carefully and solved to acceptable level. This paper is presented in the form of research proposal and overview looking into various challenging issues which are preventing the higher success in UK.

The main question to investigate is - Will mobile payments be the most preferred and acceptable next generation payment method? What are the challenges it faces with respect to Adaptability, Sustainability, Interoperability and Security? Finally introducing various methods to overcome these challenges in order to achieve state-of-the-art technology.

The objectives of this research are:

- This research will explore the various Adaptability, Sustainability Interoperability and security concerns and the obstacles to preserve these issues.Review all the literature carefully to understand the topic in depth.

- It will start with evaluation of various methods, application and services available of mobile payments at present.

- Following major issues will we looked at with the help of surveys and questioners from both demand and supply perspective.

- Customer adaptability: No matter how technology has developed the most important factor is of course the demand side. This research will focus on how much M-payments are acceptable among customers to see the present market situation (demand side).

- Sustainability: Will mobile payments remain persistent or loose out in the long run? Should mobile companies and banks invest huge amounts on this (supply side)?

- Interoperability: Mobile payments lack cohesive technology standards that can provide a universal mode of payment and requires a convergence from outside agencies. How much it has achieved and what else to research in order to achieve with regards to interoperability (supply side)?

- Security: Mobile device are prone to stealing and unauthorized access that results in safety matters and finally impacts on public confidence (both demand and supply side).

- Finally introducing cohesive technology which can be acceptable as a universal mode of M-payment across the industry without uncertainty or perplexity.

This research will primarily explore and analyze these challenge and the various methods to overcome them.

Mobile payment is a relatively new area and an extension of an Electronic payment. Mobile payment is still in its infancy stage and not a lot of work is done in this area. The objective of this research is to find out what is the present situation of the Mobile payments. This research will be useful for mobile manufacturers, financial institutions and mobile network operators. Data gathered from this research are going to reveal the truth if public is going to prefer mobile payments. If yes then what kind of expectations demand side people have from key players of mobile payment supply side members of value chain for convenient mobile payments.

Mobile network operators and banks could make decision on the base of this kind of reports that should they take risk of investing on this new payment technique in order to achieve higher revenue and business 
expansion? It is good to find out the acceptability issues before launching the new service then only the supply companies could try to make $\mathrm{M}$ - payment easier and secure. This research is providing "outside -in" in place of "inside-out". In other words it is providing the base that if there is a market of M-payments then the providing companies can make effort to boom this new technology.

\section{LITERATURE REVIEW}

\section{A. Customer adoption of mobile payment}

Mobile payments hype is attracting research fellows from varied backgrounds. This is a novice area of research and development though the literature on this topic is building up yet very conflicting and dispersed Varnali and Toker (2010). The aim of this paper is to arrange the literature on M-payments and assess this field to give research a future direction in the proposed state of art.

Using s mobile device to conduct any payment from a buyer to a seller is known as Mobile payment. It should be clearly noted that M-payment is different than M-banking. Mobile banking is offered via banks to its own customers whereas M-payment is all about making transaction using mobile phone. M-payment has its own challenges which increase its complexity and adoption. Its complexity is related to 1) competitive providers like banks and telecoms 2) two distinct adopters like end users and vendors 3 ) compatibility and standardisation of different payment methods. Mallat (2007) has analysed the complexity of these settings.

Mallat (2007) has explained in her studies about the customer adoption of modern mobile payment service. The results through her empirical and exploratory research has suggested the given advantages of mobile payments which includes time and space autonomy, accessibility, distant buying opportunities and avoiding the queues. She has found in her interview sessions that the most in demand mobile payments are micro payments (small amount payments). She has further explained that the mobile payments advantages also depend on some situations i.e. urgency or when no other payment method is available. Nevertheless there are several obstacles to the acceptability of mobile payments including complex paying process, adoption by merchants, and other supposed risks.

\section{1) Review of (Mallat 2007) research}

The nature of the above research is exploratory mainly therefore, couldn't be generalised to the public. The acceptance effects shown by her research could be further validated and verified by testing on bigger number of interviewees using quantitave methods. Furthermore dynamic characteristics could also be highlighted in future.

\section{B. Influences of Security on User Trust and Mobile Payment Adoption}

"There has been a slow acceptance of mobile and handheld devices as alternative payment systems, especially in developing countries, despite the efforts of key players such as banks, mobile network operators, and mobile payment service providers (MPSP)." Cyril et al. (2008). Therefore, Cyril et al. (2008) has provided a conceptual model to find out how security factors affect the acceptance of mobile payments.
Cyril et al. (2008) work emphasises the security issue which affects the intention of the end user to use Mobile Payment. They hope that their work would enable the key players to think of making the consumers aware of safety issues while using mobile device for payments. E-trust and web-trust would be important issues to be considered. All security mechanism should make efforts for less negative consumer experience. Security is a major issue to be considered while implementing new technology. Ease of use is a main focus of the subjective studies. In their work Cyril et al. (2008) spotlight, based on the research data, security method's effectiveness.

Cyril et al. (2008) focuses on reinforcement of controls for the purpose of risk reduction in their studies of security means. If the finance transfer is controlled it would result in mobile payment success. The main barrier here is consumers do not understand the underlying mobile technology completely and unaware of the presence of these controls. This could be done by advertisement, campaigns and hype. They have proposed various control measures.

Several marketing researchers have proved with the help of observations and experiments that there is fundamental relationship between behavioural objective and user trust.Ganesan (1994) explained that for long term course trust is the most important aspect and as a result of his study, in case of mobile payments trust is the centre point of payment intensions.

\section{1) Review of Cyril et al. (2008) work}

Although the concept of security is the main feature of building trust among customers to adopt mobile payments, not a lot of research is done till date nor perspective of consumers is explained in their paper. Issues of security and privacy are ever debating further research could be done more importantly to improve these issue in order to achieve sustainable mobile payments.

\section{The Mobile Network Operator's Viewpoint on Mobile Payment System and Mobile Business:}

This report (fig 1) is presented from Aite Group one of the biggest group deals with latest mobile commerce surveys:

"Mobile operators anticipate that $25 \%$ of subscribers will regularly use mobile banking by the end of 2009 , compared to approximately $7 \%$ at the end of 2007 , with strong growth for other mobile transaction services as well. Boston, MA, December 19, 2007 - A new report from Aite Group, LLC gauges mobile operators' current perceptions of mobile transactions."

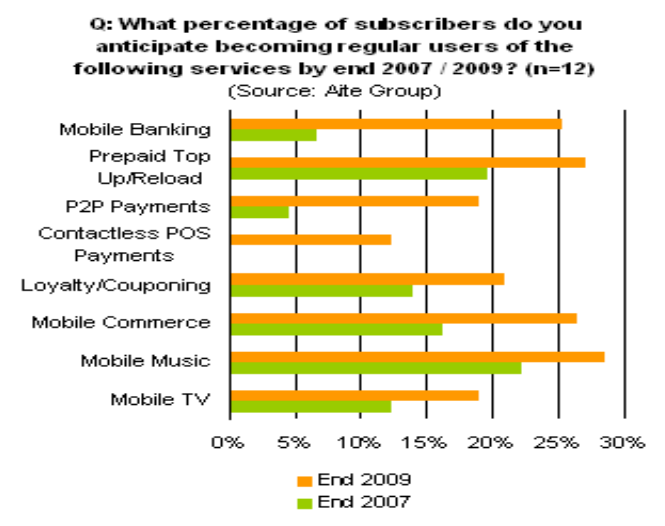

Figure 1. Aite group report of anticipated use of mobile commerce 
The following report, which is based on an October 2007 survey of 12 international mobile operators, provides insight into how mobile operators view mobile transaction adoption and how they perceive payments will be made for various mobile transaction services.

As voice revenues continue to decline for operators, a steady uptick in simple services such as text messaging provide hope that users will gradually begin to utilize hand-held devices for purposes other than that which they were originally intended. They envision that by the end of $2009,25.5 \%$ of users will use the devices for mobile banking, $26.9 \%$ will use them for the addition of prepaid minutes, and $26.3 \%$ will use them for mobile commerce. With the majority of payments being diverted to phone bills at the end of 2007, mobile operators stand to gain tremendously as mobile transactions continue to increase." Holland (2007)

\section{Different Interoperability Standards and Security Concerns: Mobile Payment Investigation:}

Zulfiquar and kadhiwal (2007) had explored the main concerns of mobile payments standardization and security.

\section{1) Security}

The security is the biggest issue in mobile payment success as it is directly linked with the user trust and various mobile payment security aspects have been presented and deployed to mobile commerce.

\section{2) "Security Properties}

A secure mobile payment system must have the following properties:

3) Confidentiality

The confidential information must be secured from an unauthorized person, process or device.

\section{4) Authentication}

Ensures parties with access to a transaction are not impostors and are trusted.

\section{5) Integrity}

The information and systems have not been altered or corrupted by outside parties.

\section{6) Authorization}

Verify that the user is allowed to make the requested transaction.

\section{7) Availability}

The system must be accessible for authorized users at any time.

\section{8) Non-Repudiation}

Ensures that the user must not deny that he/she has performed a transaction and must provide proof if such a situation occurs." Zulfiquar and kadhiwal (2007)

Grosche and Knospe (2007) Described Main Challenges to Security: when any monetary value is involved in any transaction security is must and the security measures related to mobile payment could be:

\section{9) Device Security Concerns:}

Mobile devices are prone to theft and once it has been theft all data stored in it has also gone.

\section{0) Network Technologies Security Concerns}

M-payment security could be protected by preventing the information to spread in radio environment. GSM provides security by consumer authentication mechanism and data encryption. The weakness of GSM is that there is no network authentication mechanism at the mobile station and a false station could take advantage of the situation.

\section{1) Wlan}

It operates in an unlicensed $2.4 \mathrm{GHz}$ and $5 \mathrm{GHz}$ band and it doesn't ensure any security and open to mobile data hackers.

\section{2) $\mathrm{Wep}$}

Wired equivalent policy is available to provide some level of security from IEEE but people compromise on it by providing cheaper solution.

\section{3) Bluetooth}

Bluetooth also operates in unlicensed $2.4 \mathrm{GHz}$ band and no security mechanism is recognized from blue tooth yet.

\section{4) Security of Service}

While doing monetary transactions through SMS hackers could not attach without breaking the GSM/UMTS security as SMS recognized by IMSI (international mobile subscriber identity), however this protection does not work in radio interface.

\section{5) USSD}

Unstructured supplementary service data mechanism does not have any security mechanism and depends on GSM/UMTS which exploits in radio interface again.

\section{6) Operating System Vulnerability}

Operating systems on mobile phones are not as secured as PC's. Even if operating system on mobile system is password protected it could be traced by palm crypt tool. Once password is leaked all the information is stolen.

Virus attacks is an another security threat to the Mpayments. Most of the mobile does not come with antivirus installed in it and users do not do so either in most of the cases.

\section{7) $\operatorname{Dos}$}

Denial of service attack occurs when any opposite reaction restrict the network and it becomes unavailable. This could stop the service temporary or could lead to system crash.

\section{E. Standardization and Interoperability:}

There are numerous independent approaches and standards exist for M-payment. The main reason of this inconsistency is the heterogeneous technology. Thus, there arises the problems of interoperability and integration - i.e. one system do not integrate with the system developed by the other vendor Zulfiquar and kadhiwal (2007).

\section{1) Need of Standard Interface: A Requirement Base:}

(Männle 2009; Jain et al 2008) described the need of a standard interface for the purpose of convenience and accessibility as ease of use and common platform are the key motivation for the adoption. The main reason of Mpayment failure till date is that systems do not compulsorily work together and lacking of the cohesive standards. Common platform is needed within the nation and world wide too. 


\section{ADAPTABILITY, SUSTAINABILITY, INTEROPERABILITY AND SECURITY TO M-PAYMENT}

TABLE I.

THE COMPARATIVE STUDIES OF VARIOUS M-PAYMENTS STANDARD

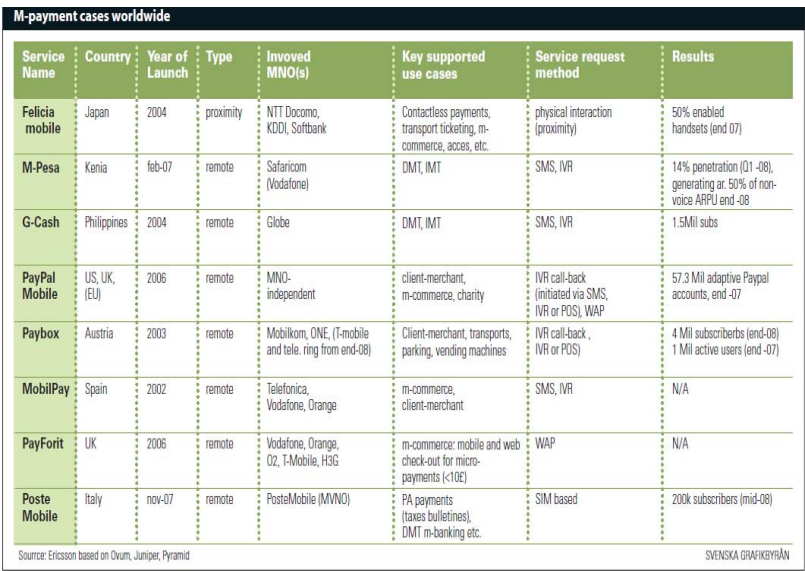

Table I (Andreoli (2008) Ericsson based on ovum, juniper, pyramid) shows the comparative studies of various M-payments standards based on services provided, country and involved MNO's.

(Jain et al 2008) has suggested the expectations of all key players related to the mobile payments it could be shown by a table (Table II).

2) Review Of The Zulfiquar And Kadhiwal (2007) And (Männle 2009; Jain Et Al 2008) Work:

M-payments are going to be sustainable and long lasting if it is beneficial and create revenue opportunities for all the key players of value chain. All the efforts such as accessibility, convenience or security will be abolished if it is not paying back to the suppliers of the service. Nevertheless if the consumers (demand side) find it unsuitable and useless and don't accept it then of course suppliers cannot do anything either. In short to be successful it has to be suitable for customers and merchants. For continued existence of this system it has be integrated with the existing systems. The customers of one mobile network must be able to use services of other mobile networks and banks. Interoperability is essential for joint effort to capture the M-payment market. Security of money transfer, interoperability of business models and reliability of the system will shape the wide acceptance of the M-payment market.

\section{Future DeVelopment Potential: M-PAyment INFLUENCING FACTORS}

(Capgemini 2008) has researched the feasibility and pleasant appearance of NFC enabled M-Payments available in Europe. In Japan, South Korea, and Far East the M-payments are already well accepted with contactless smart cards embedded mobile handsets. Market acceptance is low but with the Asian countries mobile payment, market is about to take off in Europe.

\section{A. supply-Side Technology Standardization}

"With so many M-payment standardization factors and industry bodies, there is certainly a challenge ahead to bring about industry agreement. Standardization, on matters such as integration of the secure chip holding private consumer data within handsets, is needed to boost economies of scale in order to bring down the price of chips by around $50 \%$ to below $\$ 1$ ”. (ABI research, 2006).

According to (Capgemini 2008) if we talk about NFC enabled phones "Nokia 6131 NFC "is the only phone which is NFC enabled. Others are still in their prototyping stage. We need Secure, aligned, standardized, and NFC enabled handsets in order to minimize the M-payments investment risks.

TABLE II.

EXPECTATION MATRIX

\begin{tabular}{|c|c|}
\hline Consumer & 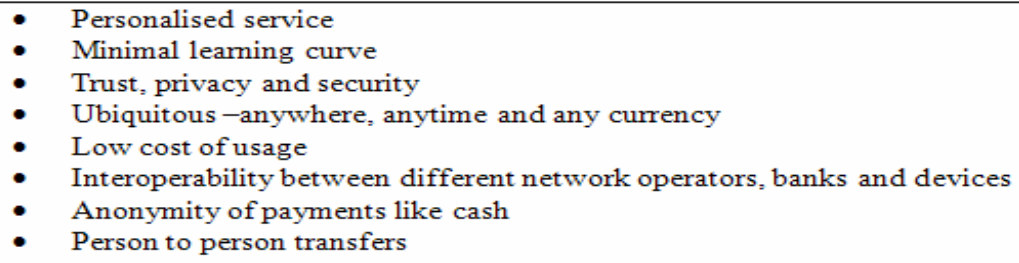 \\
\hline Merchant & $\begin{array}{l}\text { - } \quad \text { Faster transaction time } \\
\text { - } \quad \text { Low cost in using the system } \\
\text { - } \quad \text { High security } \\
\text { - } \quad \text { Customization of service } \\
\text { - } \quad \text { Real-time status of payment service }\end{array}$ \\
\hline Banks & $\begin{array}{l}\text { - Network operator independent solution } \\
\text { - } \quad \text { Payment application, designed by bank } \\
\text { - } \quad \text { Better volumes in banking } \\
\text { - } \quad \text { Customer loyalty }\end{array}$ \\
\hline Mobile service providers & $\begin{array}{l}\text { - Generating new income by increasing traffic } \\
\text { - } \quad \text { Increased ARPU and reduced chum(increased loyalty) } \\
\text { - Become an attractive partner to content providers }\end{array}$ \\
\hline Network operators & $\begin{array}{l}\text { - Integration with existing payment systems } \\
\text { - } \quad \text { Generating new income by increasing traffic } \\
\text { - } \quad \text { Become an attractive partner to content providers }\end{array}$ \\
\hline $\begin{array}{l}\text { Mobile device } \\
\text { manufacturer }\end{array}$ & $\begin{array}{l}\text { - Large market adoption with embedded mobile payment application } \\
\text { - Low time to market } \\
\text { - Increase in ARPU }\end{array}$ \\
\hline
\end{tabular}




\section{B. Financial Services Drivers}

"Financial services players themselves are making inroads into this emerging market with some new developments. The market is attractive for a number of defensive and offensive reasons. In addition to trying to drive customer revenues, most banks are striving to reduce the significance of cash and the cost of handling it. By lowering entry barriers, the harmonized Single European Payment (SEPA) infrastructure will cause major shifts in the European payment industry, and could also result in new non-banking players entering the lucrative financial services sector. In addition, the debit/credit enhanced security standard introduced by EMV (Euro Pay, MasterCard, and Visa) will force banks to replace their card payment Infrastructure, thus creating an opportunity for contactless-payments. Moreover, as already mentioned, some banks such as Rabobank are involved in launching their own MVNOs, seeing the opportunities in M-payments and using the mobile phone as a convenient communication channel to reach their customer base." (Capgemini 2008)

\section{Consumer Feedback}

According to (Capgemini 2008) there is a lot for customers in it. Accessibility, quick payment process, high efficiency, only one M-wallet to carry, good level of integrity of various faithful schemes and fast and immediate classic finance service through bank. Various survey reports have revealed that the general public is willing to adopt Mobile payments if it is an easy, accessible, low cost reachable and secure payment method. Studies indicate that young generation will look for the valid reason to choose between card and mobile payments.

"The interconnectedness between related mobile transactions services means that bundling complementary services - combining the best of communication, entertainment and other services - is likely to be an effective means of meeting consumer needs." (RFID publiek onderzoek, 2007)

\section{Success Of E-Payments And M-Payments}

Mobile device is an essential tool for the daily life now days. Now to what extent these have been adopted to indicate success. "Highlights from the report of juniper research 2008 include:

- Global annual gross transaction value will grow over 10 times between 2008 and 2013

- Juniper Research's 2008 forecasts show an increased growth rate of the global mobile subscriber base than previously, with in excess of 1 billion new users by 2013

- The top 3 regions for mobile payments (Far East \& China, W. Europe and N. America) will represent over $70 \%$ of the global mobile money transfer gross transaction value by 2013" (Juniper research 2008)

Critics of (Capgenmini 2008) work: their research reveals that according to a survey done in $30+$ countries including Europe, Asia and Africa, NFC enabled mobile payment services are still in its initial trial stage and are planned to be launched by 12 to 18 months time. The opening and acceptance of the mobile payments will be influenced by number of factors like The introduction and adoption of mobile payments will be impacted by factors such as novelty and consistency of supply side, banks and card companies dynamics, users feedback, and electronic payment agreement.

\section{The Proposed Research Method}

Research methodology will look into two problems

- Demand side (consumers) market.

- Supply side (all other key players) opportunities and concerns.

This research will follow the plan involving questionnaire and surveys. Previous works will be looked into to find out novelty use and diffusion which is concerned with this topic. Liker scale will be exploited to determine the response to questionnaires and surveys i. e. 1) $=$ Strongly Agree, 2) = Agree 3) = Neutral, 4) = Disagree, 5) = Strongly Disagree. Gender, joint earnings, job status, way of life, family structure and age of the participating members will be taken into account.

As Mobile payments are still at its infancy stage, the survey would be qualitative at this stage and the target group will be the people who may need mobile payments more often then others such as bank professional, computing professionals, university graduates and other experts to know about the demand side market. To know the suppliers wishes mobile network operators and financial institutions will be surveyed.

Written permission has already been taken from two of the lecturers to conduct survey in their classes, one of the computing company's managers is contacted and an appointment is made to visit in his organization for survey and also permission from the unit manager is taken to run a survey session in a bank's back office. The question asked in this part of the survey will be mainly related to know the customers response over Mobile payments adoption. Is there a market of Mobile payments or what areas to look at to create new opportunities in the field of mobile payments. For offline micro payments the general school children will also part of this survey as they also form a consumer group and permission is taken from one of the colleague who is secondary school head teacher to do that.

Most part of the Survey will be conducted on face to face basis as mentioned that appointments have taken from different organizations to talk to target audiences. Some part will also be done on social networking sites online and it will in the form of paid survey to get the best fruitful results. If some people are not available among target audience and their opinion do matters the survey will be conducted through paid return postage to them. The youngsters and teenagers could be driven and attracted towards surveys by offering lucrative incentives.

One of the mobile network operators is also contacted in due course to help performing this task and to get the best results. As many mobile manufacturer companies and network providers are trying to make Mobile payment successful they could reply positive. The idea here would be that the mobile network provider would throw couple of questions in the mobile bills sent to the customers and will offer a lucky draw from the ones who have responded. This company is doing it to know the market o preference of mobile payment before it can launch this service as it is also looking for some form of revenue opportunity. 
The consumer side survey will be exploring the present market preferences among users, what is their expectation and where they want mobile payments to be improved to make it sustainable and persistent.

For supply side investment the previous work has been studied thoroughly and found that banks are willing to invest on Mobile payment opportunities and some mobile network operators have taken the risk of launching it while others are "waiting to see the results." It's a kind of mix and match market at the moment from suppliers side. The main issues found from existing studies are interoperability and security issues to be sorted from supplier's side to make hit of M-payments.

To discuss and understand these issues in detail a survey questionnaire will be thrown to the main key players of the value chain such as finance institutions and mobile operators. The meeting arrangements have been made with two mobile operators, one bank and one credit card companies' sales and marketing people and the questionnaires will be targeted to them to find out what are their efforts to work with other members of value chain. What have they done to make it convenient, easy secure and trustworthy? Compare why M-payment is so popular in Asian countries and Japan. Is it because their security issues are solved? What are there movements to make one cohesive business model for providing ease of use to customers?

Data validity will be done by testing the questionnaires on mobile payment users and non users and any confusing question will be revised prior to actual survey. A pilot study will be done first on selected reliable resources and any comments from pilot studies will be included into main studies.

To ensure unbiased results willingly and unwillingly answered questions will be compared. To achieve meaningful survey results the mean values of earlier and later results will be compared. This technique will show any early and late respondent differences. It is assumed that the people who respond late are similar to those who are non responsive and could be used to achieve unbiased results.

Finally the testing will done between the early and late respondents and the difference will be determined. The solution part of the problems identified from above will be looked into once after analyzing the data from above and the work will be further done to provide suggestion on cohesive technology standards.

\section{WORK PLAN}

- 1 week for understanding and organising the overall planning steps.

- 2 weeks for literature appraisal

- 5 weeks of designing the questionnaires and Surveys and conducting them.

- 2 week to validate and verify the results

- 3 weeks to design, formulate and test the solution.

- 2 weeks to document the findings.

\section{CONCLUSION}

This research will examine and explore the various issues such as customer satisfaction and suitability of using Mobile payment. The research methodology will start initially with the reading of existing material for better understanding of the subject. Next step will consist of analyzing demand side market opportunity M-payments acceptability level among consumers and what are the advantages of using M-payments. This will be done through questionnaires and surveys. Then focusing on supply side to find out that why manufacturers, banks and mobile network operators should invest on this and identifying benefit for them for introducing payment using mobile device. Previous studies and surveys will be the base of the studies. Then it will introduce various solutions of facilitating Mobile payments by eliminating major challenges of interoperability and security along with creating market opportunities and usability.

\section{REFERENCES}

[1] (ABI research, 2006). ABI research what is next in connectivity. [Online] Available at: http://www.abiresearch.com/whitepaperDL. isp?id=19 [Accessed on: 25-April-2010]

[2] Andreoli, G. (2008) Mobile Payments - reloaded (pg1) [online] Available http://www.ericsson.com/ericsson/corpinfo/publications/ericsson business review/pdf/308/308 5457 mobile payments.pdf [Accessed on: 20-April-2010]

[3] Capgemini (2008) Mobile Payments: Are you ready for the Early Majority? Telecom \& Media Insights February 2008 capgemini consulting, technology, outsourcing [online] [4]. Available at: http://www.scribd.com/doc/9072889/Mobile-Payments-Are-YouReady-for-the-Early-Majority

[4] Cyril, U. and Gan, G.G.G. and Ademu, J. and Tella, S.A. (2008) Modeling User Trust and Mobile Payment Adoption: A Conceptual Framework Communications of the IBIMA Volume 3, [online]. Available at: http://www.ibima.org/pub/journals/CIBIMA/volume3/ v3n29.pdf 2008 [Accessed: 19-April-2010]

[5] Ganesan, S. (1994) "Determinants of long-term orientation in buyer-seller relationships," Journal of Marketing, vol. 58, pp. 119, [online]. Available at: http://www.jstor.org/ pss/1252265 [Accessed: 22-April-2010]

[6] Grosche, S. and Knospe H.(2006) Secure m-commerce scarlet ES21d, D-64307 (pg 4-7) [online] Available at: http://www.isg.rhul.ac.uk/ scarlet/documents/Secure\% $\% 20 \mathrm{~m}-$ commerce\%20 ECEJ.pdf [accessed: 17-March-2010]

[7] Holland, N. (2007) Payment Networks and Mobile Transactions: The Mobile Operator Perspective: A New Report from Aite Group December 19, 2002 [online]. Available at: http://www.aitegroup.com/reports/200712191.php [Accessed: 15March-2010]

[8] Jain, A. and Seri, S.P. and Shrinivasan, V. (2008) Mobile payments: sustainability of business models Pp: 21-23, Finsights: technology insights for the financial service industry. [Online]. Available at: Source: http://www.infosys.com/FINsights/pdf/issue3/FINsights-Chp2.pdf [Accessed: 19-April-2010]

[9] Mallat, N. (2007) Exploring Consumer Adoption of Mobile Payments - A Qualitative Study Helsinki School of Economics, volume 16, [online]. Available at: http://project.hkkk.fi/ helsinkimobility/papers/Mobile\%20Applications_2_3.pdf [Accessed: 21-April-2010:19:30]

[10] Mallat, N. Tuunainen,V.K.(2007) Exploring Merchant Adoption of Mobile Payment Systems: An Empirical Study e-Service Journal - Volume 6, Number 2, winter 2007, pp. 24-57 [online]. Available

http://muse.jhu.edu/journals/eservice journal/toc/esj.6.2.html [Accessed: 22-April-2010]

[11] Männle, M. 2009, Interoperable Mobile Payment - A Requirements - Based Architecture Encorus Technologies GmbH; product management Payment Platform [online] Available at http://maennle.org/manfred/publications/20030917 WI2003 Full Paper.pdf [Accessed: 23-March-2010]

[12] Tomi, A.T and Kasper, T. Melkko, and S. (2004) $3 G$ Marketing: Communities and Strategic Partnership, John Wiley and Sons Ltd. 
EXPLORING THE KEY CHALLENGES:

\section{ADAPTABILITY, SUSTAINABILITY, INTEROPERABILITY AND SECURITY TO M-PAYMENT}

[13] (RFID publiekonderzoek, 2007) [Online] Available at: http://rathenauinstituut.com/showpageproject.asp?steID $=1 \& I D=20$ 29 [Accessed on: 20-April-2010]

[14] Varnali, K and Toker, A (2010), Mobile marketing research: Thestate-of-the-art, International Journal of Information Management Volume 30, Issue 2, April 2010, Pages 144-151 [Accessed: 07March-2011] doi:10.1016/j.ijinfomgt.2009.08.009

[15] Wilcox, H. (2008) Press Release: Juniper Research Forecasts Total Mobile Payments to Grow Nearly Ten Fold by 2013 [online] Available

at: http://www.juniperresearch.com/shop/viewpressrelease.php? pr=106 [Accessed on: 22-April-2010]

[16] Zulfiquar, A.U.S. and Kadhiwal, S. (2007) Computer fraud and security: Analysis of mobile payment security measures and different standards, paper from Ali Bhutto Institute of Science and Technology, Karachi, Pakistan, June 2007 (pg 14, 15) Available at: Science Direct.

\section{AUTHORS}

Rashmi Mantri and Junkang Feng are with the Database Research Group, School of Computing, University of the West of Scotland, UK, \{Rashmi.mantri, Junkang.Feng@uws.ac.uk\}.

Received August $28^{\text {th }}, 2010$. Published as resubmitted by the authors March $24^{\text {th }}, 2011$. 